\title{
Art of Scientific Writing
}

\section{S. P. Somashekhar ${ }^{1}$}

Published online: 6 April 2020

(C) Association of Gynecologic Oncologists of India 2020

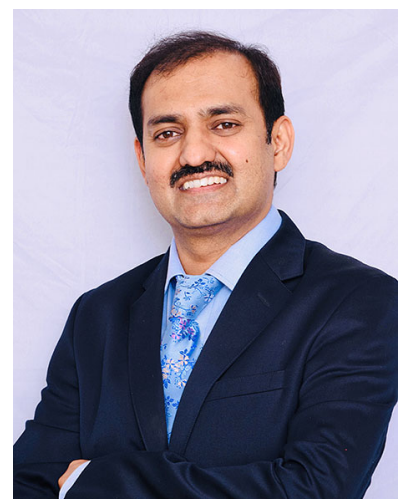

Scientific writing is an essential component of medical research as it determines the success or failure of a trial. Scientific writing is the process of the development of publications that deal precisely with medicine or health care [11]. Publishing of the medical outcomes is important to communicate research findings. Writing a scientific publication is a challenging procedure that the surgeons may lack to report $[9,5]$. The skills of a surgeon as a scientific writer should be advanced. Writing and getting published the research findings is an interesting and gratifying process of continuous learning and improvement. Publishing a research finding in a good scientific journal requires strong background of science and an effective strategy that includes generation of ideas and their implementation. The period for becoming a skillful scientific writer is generally long and needs conscious self-learning $[2,11]$.

Lack of proficiency in scientific writing skills results in confusing conclusions leading the scientific manuscripts to data dumps. Lack of originality and presentation of obsolete result are the main reasons for rejection of scientific manuscript [1]. The preparation of medical research

S. P. Somashekhar

somusp@yahoo.com

1 Department of Surgical Oncology, Manipal Comprehensive Cancer Centre, Manipal Hospital, Airport Road, Bangalore 560 017, India manuscript is often taken lightly, and it leads to several problems such as multiple rejections from scientific journals [4]. Lack of attention and failure to follow the field of the manuscript lead to rejection. Generally, insertion of voluminous text in a manuscripts walks away from the objective, mentioning the details that are not within the scope of the trial. Unclear writing in medical research is usually difficult to interpret, and it may transfer misleading information [1].

The primary criteria for acceptation the scientific manuscript are novelty and unobviousness. The scientific writer should have an adequate knowledge of how to interpret the results of the research outcome [1]. If the results observed are out of specifications, the writer should critically interpret the cause of negative results. A research manuscript with undesirable results may support future investigation if the writer exactly interprets the root cause of these results. The common reason for rejection of a research manuscript includes: (a) journal's aim,(b) writing is unconceivable; (c) the writing style of the journal is different; (d) results doesn't add value to the journal; (e) unclear hypothesis; (f) wrong methodology; (f) poor analysis; (g) inconclusive result; (h) and violation of research ethics [8].

Writing does not come naturally for few researchers, and they need to be aware of few basic rules in addition to regular practice. A good scientific writer has the capability to report the research outcomes at the highest level [12]. Surgeons or other scientific writers report their research outcomes in a better way only if they have acquired the essentials of the art of good scientific writing [10]. The set of abilities required for a skilled surgical writing includes logic, clarity, organization and precision. A good surgical scientific writer can only communicate his message to intended audience in a better way [3]. A scientific writer requires a combination of competences, such as understanding of the field, writing skills, the knowledge of scientific guidelines and the aptitude to understand, analyze and report the scientific results in the required format [11]. 
Many sources are available for the scientific writers to get the required writing skills. The scientific writer needs to have a clear thoughtfulness of the concepts and ideas and should present the research outcomes in a way to be easily understood [5]. Nearly all the manuscripts are prepared in the IMRAD structure: Introduction, Methods, Results and Discussion. Organize your manuscript under these heads. The information presented in the manuscript should suit the understanding level of the target audience [4]. The qualities that distinguish a good scientific writer from an ordinary one include: (a) understanding of the purpose of the trial,(b) in-depth research of the subject,(c) ability to think and organization of ideas and (d) ability to write the research finding in a suitable level.

IMRAD structure for writing a scientific manuscript:

Introduction

Earlier research findings

Generation of hypotheses

Methods

Details of patients population

Procedure and instrument details

Results

Explanation of research outcomes

Statistical significance

Discussion

Confirmation of hypotheses

Comparison to other's research outcomes

Well-written research manuscript helps in advancing the knowledge of medical community. The important fundamentals in writing a scientific publication include: (a) reading of good scientific publication; (b) finding the basics of research, planning and execution of hypothesis and collecting and reporting the results; (c) interpretation and presentation of the research outcomes with accuracy, grammar and flare; (d) clearly expressing and effectively delivering the research outcomes; (e) consideration to details and clarity in writing and unbiasedness; (f) and reporting of organized information such as background, medical history, physical examination, treatment delivered and opinion $[2,5]$.

Levels for preparation of a scientific manuscript:

\begin{tabular}{|c|c|c|}
\hline Pre-writing level & Writing level & $\begin{array}{l}\text { Post-writing } \\
\text { level }\end{array}$ \\
\hline Data evaluation & Write as per IMRAD & Submit to journal \\
\hline Select journal & Proofread & Acceptance \\
\hline $\begin{array}{l}\text { Read author's } \\
\text { instructions }\end{array}$ & Review & Published \\
\hline
\end{tabular}

A surgeon is also supposed to maintain the ethical standard, as in surgery he deals with confidential issues related directly to patient's identity, history, behavior and disease. Ethical and legal issues that should be considered by scientific writer include: (a) giving honest information including negative results, copyright laws, avoiding plagiarism, ensuing authorship criteria and valuing journal review process [7]. Inclusion and exclusion criteria should be clearly defined. Details of study period, ethics committee clearance, informed consent form, sample size and randomization/masking methods should be properly explained. Details of clinical studies conducted in compliance with ethical principles mentioned of Declaration of Helsinki, GCP and the other applicable regulatory requirement should be adequately described in the manuscript. Authorship issues if exist should be settled as soon as possible. To avoid these issues, a scientific writer must be adherent to the specific publication guidelines such as CONSORT (for randomized controlled trials), STROBE (for observational studies), PRISMA (for systematic reviews and meta-analyses) and STARD (for studies of diagnostic accuracy) [6].

Summary and recommendations for medical professionals before writing and publishing:

Think about the target audience and the level of scientific work

Draft the manuscript according to IMRAD structure: organize the manuscript sections so that they tell a story

Critically review and finalize the abstract

Report research outcomes clearly and concisely

For research manuscript, adequate numbers should be used to validate sound statistical conclusions

Avoid ethical issues: informed consent form, IEC approval, disclosure of conflict of interest, acknowledgment of funding sources

Rewrite and proofread for improvement, and check all numbers for accuracy and consistency

Give credit to the ideas, methods and results of other researchers

If English is not author's first language, then identify a native English speaker to review the language of the manuscript before submitting to the target journal

Follow the author's guidelines and format the manuscript accordingly—it makes the editor's job easier

In conclusion, scientific writing is both a science and an art. Publishing in scientific manuscript in scientific journal is a way to network within the target audience. Scientific writing requires an in-depth knowledge of specific requirements for research outcomes. Scientific writing requires understanding of research methodologies, procedures and awareness of relevant guidelines. For patients 
and the target audiences, it is the source of all healthrelated knowledge, information and education. Scientific writing is a complex process, from the foundation of an idea, to the practical implementation at the time of writing and lastly to the publication of the manuscript in the scientific journal. Scientific writing is an important tool for reporting vivacious information that helps the community lead a healthy and meaningful life.

Funding No funding.

\section{Compliance with ethical statement}

Conflict of interest The authors declare that there is no conflict of interest.

\section{References}

1. Ali J. Manuscript rejection: causes and remedies. J Young Pharm. 2010;2(1):3-6.

2. Balakumar P, Inamdar MN, Jagadeesh G. The critical steps for successful research: the research proposal and scientific writing:
(A report on the pre-conference workshop held in conjunction with the 64(th) annual conference of the Indian Pharmaceutical Congress-2012). J Pharmacol Pharmacother. 2013;4(2):130-8.

3. Derish P, Eastwood S. A clarity clinic for surgical writing. J Surg Res. 2008;147(1):50-8.

4. Dhammi IK, Rehan-Ul-Haq. Rejection of Manuscripts: Problems and Solutions. Indian J Orthop. 2018;52(2):97-9.

5. Hoogenboom BJ, Manske RC. How to write a scientific article. Int J Sports Phys Ther. 2012;7(5):512-7.

6. Johansen M, Thomsen SF. Guidelines for reporting medical research: a critical appraisal. Int Sch Res Not. 2016;2016:1346026.

7. Kumar R, Attri S, Hastir H, Goyal S. Surgical ethics-Indian perspective. IJCMR. 2017;4(5):77-83.

8. Kumar VP, Rao CS. A review of reasons for rejection of manuscripts. J Res Sch Prof Eng Lan Tea. 2018;8(2):1-11.

9. Quinn CT, Rush AJ. Writing and publishing your research findings. J Investig Med. 2009;57(5):634-9.

10. Sengupta S, Shukla D, Ramulu P, Natarajan S, Biswas J. Publish or perish: the art of scientific writing. Indian J Ophthalmol. 2014;62(11):1089-93.

11. Sharma S. How to become a competent medical writer? Perspect Clin Res. 2010;1(1):33-7.

12. Zhang W. Ten simple rules for writing research papers PLoS Comput Biol. 2014;10(1):e1003453.

Publisher's Note Springer Nature remains neutral with regard to jurisdictional claims in published maps and institutional affiliations. 